\title{
Applying of an Adaptive Neuro Fuzzy Inference System for Prediction of Unsaturated Soil Hydraulic Conductivity
}

\author{
Mohamed A. Al-Sulaiman \\ Community College, Huraimla, Shaqra University, P.O. Box 300, Huraimla 11962, Saudi Arabia. \\ DOI: http://dx.doi.org/10.13005/bbra/1899
}

(Received: 19 October 2015; accepted: 20 November 2015)

\begin{abstract}
The unsaturated hydraulic conductivity of soil $\left(\mathrm{K}_{\mathrm{u}}\right)$ is one of the most principal parameters in the study of water movement in the soil. The field measurement methods of $\left(K_{u}\right)$ are hard and expensive. So, indirect prediction of $\left(K_{u}\right)$ has received considerable attention as published in the research papers to be an alternative approach. However, prediction models for soil hydraulic conductivity are now widely used informative tools for rapid and cost-effective assessment. Thus in this study, an attempt has been made to apply an adaptive neuro-fuzzy inference system (ANFIS) for predicting $\left(K_{u}\right)$. The input variables were ECRatio (electric conductivity of water divided by electric conductivity of soil), SARRatio (sodium adsorption ratio of water divided by sodium adsorption ratio of soil), soil texture index (calculated from clay, sand and silt), suction rate, organic matter in the soil, initial soil moisture content and initial soil bulk density. The Gaussian membership function was the best for the input variables. The Hybrid learning was selected for predicting $\left(K_{u}\right)$ with ANFIS. Three performance functions namely; root mean squared error (RMSE), mean error (ME) and coefficient of determination $\left(R^{2}\right)$, were used to evaluate the predictive capability of the suggested (ANFIS). The obtained results for testing data ( 9 points) indicated that the $R^{2}$ values relating predicted versus measured estimates of $\left(K_{u}\right)$ was 0.783 , ME was found to be $0.118 \mathrm{~cm} / \mathrm{sec}$ and RMSE was found to be $0.472 \mathrm{~cm} / \mathrm{sec}$. As a result, it appears that applying ANFIS suggests a new approach for determining $\left(\mathrm{K}_{\mathrm{u}}\right)$ along with saving time and cost.
\end{abstract}

Key words: Soil and water samples; Adaptive Neuro-Fuzzy Inference System (ANFIS).

Knowing hydraulic properties of a soil is play an important role on solving many water management problems during applying soil water flow models (Torabi et al., 2006). Soil hydraulic conductivity represents in two forms namely: saturated hydraulic conductivity and unsaturated hydraulic conductivity (Zhuang et al., 2001). However, the most important soil hydraulic parameters is unsaturated hydraulic conductivity as it characterizes the ability of soil to conduct water when soil pore space is not fully filled with water (Guber, 2007). Additionally, quantifying

\footnotetext{
* To whom all correspondence should be addressed. E-mail: mohazizsu@yahoo.com
}

unsaturated water flow into soil pores requires knowledge of soil hydraulic conductivity (Dane and Topp, 2002). So, equations were proposed to predict unsaturated soil hydraulic conductivity (Amer et al., 2009; Amer et al., 2014).

Direct measurement of soil hydraulic properties in the laboratory or in the field is time consuming and subject to large error (Jabro, 1992). In addition, such measurement of hydraulic conductivity of soil is difficult, tedious, relatively costly, labour intensive and time-consuming (Lakzian et al., 2010; Emami et al., 2012; Kalkhajeh et al., 2012; Fereshte, 2014;Siltecho et al., 2014). Thus, indirect methods using predictive approaches have been developed for estimation of hydraulic properties of soil from easily measurable soil properties (Schuh and Bauder, 1986; 
Vereecken et al., 1990; Vereecken, 1995). Indirect estimations of the hydraulic conductivity function have gained considerable attention and efforts have been made by researchers to improve the estimates (Skaggs et al., 2001).

A literature review shows that most studies in this line of research have used ANN (Tamari et al., 1996; Ghanbarian-Alavijeh et al., 2010, Moosavi and Sepaskhah, 2012; Nosrati et al., 2012), multiple linear regression technique (Jabro, 1992) and support vector machine (SVM) and a nonlinear statistical regression approach (Elbisy,2015) for predicting the soil hydraulic conductivity.

For describing relationships between different combinations of inputs and outputs such as those that must be determined for accurately predicting soil hydraulic conductivity, ANN is currently the most widely used technique (Erzin et al., 2009; Moosavi and Sepaskhah, 2012). Since Zadeh (1965) proposed the fuzzy logic approach to describe complicated systems, it has become popular and been successfully used to solve prediction purposes in various agricultural and engineering problems (Sarmadian and Mehrjardi, 2010). A recent literature review shows that the use of adaptive-network-based fuzzy inference system (ANFIS) (Jang, 1993; Ho et al., 2011) for such purposes is relatively rare and applied in predicting soil properties in the conditions where there isn't enough information about how parameters relate to each other (El Awady et al., 2002; Minasny et al., 2004; A kbarzadeh et al., 2009; Sezer et al., 2009; Anari et al., 2011; Yilmaz and Kaynar, 2011; Kalkhajeh et al., 2012; Moosavi and Sepaskhah, 2012; Xue and Yang, 2013).

Soft computing techniques such as adaptive neuro-fuzzy inference system (ANFIS) are new developed methods which probably can be used for prediction of soil properties (Minasny et al., 2004; Azamathulla et al., 2009). This study was, therefore, conducted to investigate the efficacy of ANFIS technique in developing prediction functions for estimating unsaturated soil hydraulic conductivity. However, ANFIS has shown potential in modeling nonlinear functions. It learns features of the data set and adjusts the system characteristics according to a given error criterion (Jang, 1993).

\section{Adaptive neuro-fuzzy inference system architecture}

Using a given input-output data set, ANFIS build a fuzzy inference system whose membership function parameters are adjusted through the learning process (Mohdeb and Mekideche, 2010). Figure (1) illustrates ANFIS architecture for Takagi-Sugeno type fuzzy inference system, where nodes of the identical layer have the same functions. In general, neuro-fuzzy system has input and output layers, and three hidden layers that represent membership functions and fuzzy rules. Each node in a layer receives input signals from a previous layer and transmits its output signals to nodes in the next layer (Mohdeb and Mekideche, 2010). In the adaptive network, the circle nodes describe fixed nodes and square nodes describe adaptive nodes.

Adaptive nodes have parameter sets while fixed nodes have none. The parameter sets are computing according to given training data and a learning procedure for complete a desired input-output data set (Mohdeb and Mekideche, 2010). For a first-order Sugeno model, a common rule set with two fuzzy if-then rules is as follows:

Rule 1: If $x_{1}$ is $A_{1}$ and $x_{2}$ is $B_{1}$, then

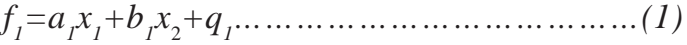

Rule 2: If $x_{1}$ is $A_{2}$ and $x_{2}$ is $B_{2}$, then

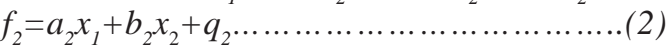
where, $x_{1}$ and $x_{2}$ are the crisp inputs to the node and $A_{1}, B_{1}, A_{2}, B_{2}$ are fuzzy sets, $a_{i}, b_{i}$ and $q_{i}(\mathrm{i}=1,2)$ are the coefficients of the first-order polynomial linear functions. Structure of a two-input first-order Sugeno fuzzy model with two rules is shown in Figure (1) and consists of five layers (Jang, 1993). In the first layer (fuzzy layer), $\mathrm{x} 1$ and $\mathrm{x} 2$ are the inputs of adaptive nodes $\mathrm{Ai}$ and $\mathrm{Bi}$, respectively. $\mathrm{Ai}$ and $\mathrm{Bi}$ are the linguistic labels used in the fuzzy theory for describing the membership functions. The five layers of ANFIS model are as follows:

Layer1: (Input nodes): Each node output in this layer is fuzzified by membership grade of a fuzzy set corresponding to each input.

or

$$
O_{i, 1}=\mu_{A i}\left(x_{1}\right) \quad \mathrm{i}=1,2
$$

$$
O_{j, 1}=\mu_{B j}\left(x_{2}\right) \quad \mathrm{i}=1,2
$$

Where, $x_{1}$ and $x_{2}$ are the inputs to node $\mathrm{i}(\mathrm{i}$ $=1,2$ for $x_{1}$ and $\mathrm{j}=1,2$ for $\left.x_{2}\right)$ and $x_{1}\left(\right.$ or $\left.x_{2}\right)$ is the input to the $\mathrm{i}^{\text {th }}$ node and $A_{i}$ (or $\left.B_{j}\right)$ is a fuzzy label. 
Layer 2 (Rule nodes): Each node output in this layer represents the firing strength of a rule, which performs fuzzy, AND operation. Each node in this layer, labeled $\boxplus$, is a stable node which multiplies incoming signals and sends the product out.

$$
O_{2, i}=W_{i}=\mu_{A i}\left(x_{1}\right) \mu_{B i}\left(x_{2}\right) \quad i=1,2
$$

Layer 3 (Average nodes): In this layer, the nodes calculate the ratio of the $i^{\text {th }}$ rules firing strength to the sum of all rules firing strengths

$$
O_{3, i}=\overline{W_{i}}=\frac{w_{i}}{w_{1}+w_{2}} \quad i=1,2
$$

Layer 4 (Consequent nodes): In this layer, the contribution of $\mathrm{i}^{\mathrm{t}}$ rules towards the total output or the model output and/or the function calculated as follows: Where, is the output of Layer 3 and $a_{i}$, $b_{i}, q_{i}$ are the coefficients of linear combination in Sugeno inference system. These parameters of this layer are referred to as consequent parameters.

$$
O_{4, i}=\bar{W}_{i} f_{i}=\bar{W}\left(a_{1} x_{1}+b_{1} x_{2}+q_{i}\right) \quad i=1,2
$$

Layer 5: (Output nodes): The node output in this layer is the overall output of the system, which is the summation of all coming signals

$$
O_{5, i}=Y=\sum_{1}^{2} \bar{W}_{i} f_{i}=\frac{\sum_{1}^{2} \overline{W_{i}} f_{i}}{\sum_{1}^{2} \overline{W_{i}}}
$$

\section{MATERIALSAND METHODS}

\section{Soil and water samples characteristics and the select input variables}

The experiments were conducted on soils located at different sites in Saudi Arabia during year of 2015. However, the experiments were conducted in the field. Three samples of the studied soil were taken by augur from the top 20 $\mathrm{cm}$ for soil moisture content and soil bulk density analysis. Other samples were taken for textural analysis, which showed that the samples could be classified as sand, sandy loam, loam and loamy sand. The initial soil water content (dry base) of the samples was measured by the help of electric oven for $24 \mathrm{~h}$ at $105^{\circ} \mathrm{C}$. The characteristics of water used in filed experiments were measured in the laboratory using the standard methods.

To represent all soil components (sand, silt and clay) in one index, a soil texture index was determined (Oskoui and Harvey, 1992) to represent soil texture components as follows:

$$
S T I=\frac{\log \left(S_{i}{ }^{C C_{a}}\right)}{100}
$$

Where $S_{i}$ and $C C_{a}$ are \% of silt and clay fractions in the soil, respectively. Meanwhile, the sand fraction is represented implicitly since the sum of sand, silt and clay fractions is always constant. Oskoui and Harvey (1992) showed that the STI reflects the effects of all three the soil fractions. The STI produces unique numbers for every combination of sand, silt and clay contents. Sodium adsorption ratio (SAR) is a measure of the sodicity of soil, as determined from analysis of water extracted from the soil. The formula for calculating sodium adsorption ratio for water and soil is as follows (Suarez et al., 2008):

$$
S A R=\frac{N a^{+}}{\sqrt{\frac{1}{2}\left(\mathrm{Ca}^{++}+M g^{++}\right)}}
$$

Where $\mathrm{Na}^{+}, \mathrm{Ca}^{++}$, and $\mathrm{Mg}^{++}$represent concentrations expressed in milliequivalents per liter (meq/L).

By the help of the obtained water and soil salinities, the ECRatio (electric conductivity of water divided by l electric conductivity of soi) was determined to be the first input variable. Also, SARRatio (sodium adsorption ratio of water divided by sodium adsorption ratio of soil) was determined to be the second input variable. STI which calculated from clay, sand and silt was considered to be the third input variable. The rest input variables were suction rate (SR), organic matter in the soil (OM), initial soil moisture content (MC) and initial soil bulk density (BD). The combination during field experiments created 148 data points. Table (1) illustrates some of values of input variables and output variable.

\section{Measurement of unsaturated soil hydraulic conductivity in the field}

The unsaturated soil hydraulic conductivity $\left(\mathrm{K}_{\mathrm{u}}\right)$ was measured in the field (Figure 2) using a mini disk infiltrometer (Decagon Devices 
Inc.) with assistance of some calculations which are provided as excel worksheet soil (Decagon Devices Inc., 2012). The mini disk infiltrometer consists of two chambers (water reservoir and bubble chamber), which are connected via a Mariotte tube to provide a constant water pressure head of -0.5 to $-7 \mathrm{~cm}$ (equivalent to -0.05 to -0.7 $\mathrm{kPa}$ ).The bottom of the mini disk infiltrometer contains a porous sintered steel disk. The water filled tube is placed upon the soil surface (Figure 2 ) resulting in water infiltrating into the soil, with the volume of water and speed of infiltration depending on the sorptivity and hydraulic conductivity of the soil. A pressure head (suction rate) of -1 to $-6 \mathrm{~cm}$ (equivalent to -0.1-0.6 kPa) was chosen in this study. All measurements within one sample test were taken on the same day. The mini disk infiltrometer measurements were taken three times for every soil sample. During the measurement, the volume of the water in the reservoir chamber was documented in regular intervals.

\section{Calculating of unsaturated soil hydraulic conductivity $\left(\mathbf{K}_{\mathrm{u}}\right)$}

The method proposed by Zhang (1997) is

quite simple and works well for measurements of infiltration into dry soil from the recorded data by mini disk infiltrometer (Decagon Devices, 2012). The method requires measuring cumulative infiltration vs. time and fitting the results with the function:

$$
I=C_{1} t+C_{2} \sqrt{t}
$$

Where I is the cumulative infiltration $(\mathrm{cm})$, $\mathrm{t}$ is the time (sec), and $\mathrm{C}_{1}(\mathrm{~cm} / \mathrm{sec})$ and $\mathrm{C}_{2}\left(\mathrm{~cm} / \mathrm{sec}^{-}\right.$ ${ }^{0.5}$ ) are parameters. $\mathrm{C}_{1}$ is related to hydraulic conductivity and $\mathrm{C}_{2}$ is related to soil sorptivity. The hydraulic conductivity (K) of the soil is then computed from

$$
K=\frac{C_{1}}{A}
$$

Where $C_{1}$ is the slope of the curve of the cumulative infiltration vs. the square root of time and (A) is a value relating the van Genuchten parameters for a given soil type to the suction rate and radius of the infiltrometer disk. (A) is computed from:

$$
A=\frac{11.65\left(n^{0.1}-1\right) \exp \left[2.92(n-1.9) \alpha h_{0}\right]}{\left(\alpha r_{0}\right)^{0.91}} \quad n \geq 1.9 \ldots
$$

$A=\frac{11.65\left(n^{0.1}-1\right) \exp \left[7.5(n-1.9) \alpha h_{0}\right]}{\left(\alpha r_{0}\right)^{0.91}} \quad n<1.9$

Where $n$ and $\alpha$ are the van Genuchten parameters for the soil, $r_{0}$ is the disk radius and $h_{o}$ is the suction at the disk surface.

Building of adaptive neuro-fuzzy inference system (ANFIS) for unsaturated soil hydraulic conductivity prediction

In the current study, ANFIS was used to model the relationship between inputs represented characteristics of irrigation water and soil and actual field measurements of unsaturated soil hydraulic conductivity under no changes of the soil conditions. The model was implemented using the fuzzy logic toolbox of MATLAB (2002), a Sugeno type of approach (Takagi and Sugeno, 1985). To construct ANFIS model, the obtained field data were divided into two different groups: training and testing. The training data matrix was composed of 139 data points. 9 data points, which are different from the training data, were used for the testing of the ANFIS model. There are no fixed rules for developing an ANFIS model (Yan et al., 2010).

ANFIS model developed in this research has seven inputs (ECRatio, SARRatio, STI, SR, $\mathrm{OM}, \mathrm{MC}, \mathrm{BD}$ and an output $\left(\mathrm{K}_{\mathrm{u}}\right)$ as depicted in Figure (3). The numerical ranges for each input were for ECRatio (0.05-3.35 dimensionless), for SARRatio (0.07-2.97 dimensionless), for MC (5.35$15.16 \% \mathrm{db})$, for BD $\left(1.22-1.77 \mathrm{~g} / \mathrm{cm}^{3}\right)$, for STI (0.02535-0.1535 dimensionless), for OM (0.97$3.73 \%)$ and for SR (-1: $-6 \mathrm{~cm})$. For the determination of the best fit in the fuzzy model, types of membership function for input are changed. The "gaussmf" membership functions were the best for each input.

A hybrid learning algorithm was employed to train the ANFIS model. In the ANFIS training process, each epoch is composed from a forward pass and a backward pass. In the forward pass, a training set of input patterns (an input vector) is presented to the ANFIS, neuron output is calculated on the layer-by-layer basis, and rule consequent parameters are identified. As soon as the rule consequent parameters are established, an actual network output vector, $y_{d}$, is computed and the error vector $(e)$ is determine as $\left(e=y_{d}-y_{n}\right)$ as $y_{n}$ is actual output. This process finishes at desired epochs (Jang, 1993). 
ECRatio, SARRatio, STI, OM, MC and BD inputs were divided into two Gaussian memberships with two linguistic terms $\{$ Small $(\mathrm{S})$, High $(\mathrm{H})\}$. Meanwhile, SR input was divided into four Gaussian membership with four linguistic terms \{Small (S), Medium (M), High (H) and very high (VH)\}. The training error was 0.00259636 when the type of the membership function was "gaussmf" and output membership function was linear. The final membership functions of the model are shown in Fig. (4).

Specifications of the developed ANFIS are as follows

1. Number of nodes: 554

2. Number of linear parameters: 2048

3. Number of nonlinear parameters: 32

4. Total number of parameters: 2080

5. Number of training data pairs: 139

6. Number of fuzzy rules: 256

A plot of the estimated unsaturated soil hydraulic conductivity predicted by the ANFIS model

from training data versus actual unsaturated soil hydraulic conductivity (Figure 5) shows that the model captured the relationship between the input parameters and unsaturated soil hydraulic conductivity. The correlation $\mathrm{R}$ was 1 . This value shows that ANFIS can predict the unsaturated soil hydraulic conductivity with a high accuracy. However, training data marked with (o) sign and the check data indicated with the plus sign (+) in the Figure (5).

\section{Statistical performance evaluation criteria}

The performance of the developed model is examined using some statistical measures that are well known in literature such as root mean square error (RMSE) and mean error (ME). However, ME has a unit and it is expressed as:

$$
M E=\frac{\sum_{j=1}^{n}\left(Y_{j}-\hat{Y}\right)}{n}
$$

Where, $\mathrm{Y}$ and $\hat{Y}$ are the actual and predicted values, respectively and $n$ is the number of observations. Root mean square error (RMSE) yields the residual error in terms of the mean square error expressed as,

$$
R M S E=\sqrt{\frac{\sum_{j=1}^{n}\left(Y_{j}-\hat{Y}_{j}\right)^{2}}{n}}
$$

\section{RESULTSAND DISCUSSION}

\section{Descriptive statistics}

Descriptive statistics of the used data are shown in Table (2). As indicated from this table, the initial soil moisture content values in the studied soil samples ranged between $5.35 \% \mathrm{db}$ and $15.16 \% \mathrm{db}$ with an average value of $10.4 \% \mathrm{db}$. It was also found that the OM in the studied soils is

\begin{tabular}{|c|c|c|c|c|c|c|c|}
\hline \multicolumn{7}{|c|}{ Input variables } & \multirow{2}{*}{$\begin{array}{l}\text { Output variable } \\
\qquad \log K_{U}\end{array}$} \\
\hline ECRatio & SARRatio & STI & SR & $\mathrm{OM}$ & MC & $\mathrm{BD}$ & \\
\hline$(-)$ & $(-)$ & $(-)$ & & $\%$ & \%db & $\mathrm{g} / \mathrm{cm}^{3}$ & $\mathrm{~cm} / \mathrm{sec}$ \\
\hline 1.11 & 0.72 & 0.07236 & 4 & 1.95 & 12.54 & 1.65 & -3.11993 \\
\hline 1.11 & 0.72 & 0.07236 & 5 & 1.95 & 13.67 & 1.55 & -3.29847 \\
\hline 0.90 & 0.51 & 0.07236 & 3 & 1.95 & 11.63 & 1.60 & -3.04095 \\
\hline 0.66 & 0.37 & 0.07236 & 1 & 1.95 & 14.50 & 1.56 & -3.15499 \\
\hline 0.66 & 0.37 & 0.07236 & 3 & 1.95 & 13.01 & 1.56 & -3.20755 \\
\hline 0.66 & 0.37 & 0.07236 & 6 & 1.95 & 12.00 & 1.55 & -3.61421 \\
\hline 0.47 & 0.45 & 0.07236 & 1 & 1.95 & 10.32 & 1.63 & -2.74532 \\
\hline 0.47 & 0.45 & 0.07236 & 2 & 1.95 & 10.05 & 1.58 & -2.77886 \\
\hline 0.47 & 0.45 & 0.07236 & 4 & 1.95 & 8.07 & 1.65 & -3.0361 \\
\hline 0.47 & 0.45 & 0.07236 & 5 & 1.95 & 13.04 & 1.52 & -3.23777 \\
\hline 0.87 & 0.61 & 0.07236 & 1 & 1.95 & 10.82 & 1.63 & -2.63068 \\
\hline 0.87 & 0.61 & 0.07236 & 2 & 1.95 & 8.73 & 1.49 & -2.70512 \\
\hline 0.87 & 0.61 & 0.07236 & 3 & 1.95 & 11.16 & 1.57 & -3.0156 \\
\hline 0.87 & 0.61 & 0.07236 & 5 & 1.95 & 10.81 & 1.59 & -3.4234 \\
\hline 0.87 & 0.61 & 0.07236 & 6 & 1.95 & 12.29 & 1.53 & -4.52031 \\
\hline
\end{tabular}

Table 1. Some of values of input and variables output variable. 
low, ranging from $0.97-3.75 \%$, with an average of $2.19 \%$. Additionally, initial soil bulk density of the studied soils was in the range of $1.22-1.77 \mathrm{~g} / \mathrm{cm}^{3}$ with an average value of $1.64 \mathrm{~g} / \mathrm{cm}^{3}$. The ECRatio (irrigation water salinity divided by soil salinity) was in the range of $0.051-3.348$ dimensionless with an average of 1.22 dimensionless. However the studied range of ECRatio could be allow to use different irrigation water salinity in different soil salinity to get wide range ECRatio. Moreover, SARRatio (sodium adsorption ratio of water divided by sodium adsorption ration of soil) was in the range of 0.075-2.97 dimensionless with an average of 1.4 dimensionless. However the studied range of SARRatio could be allow to use different irrigation water quality in different soil having different percentages of sodium concentration to get wide range of SARRatio. Additionally, STI (calculated from clay sand and silt) was in the range of 0.0254-0.1535 dimensionless with an average of 0.07 dimensionless. However, STI allows different soils could be tested. Table (2) revealed that there was little variability in the sample distributions of the variables used in this study to develop unsaturated soil hydraulic conductivity prediction models, indicating that their values were all

Table 2. Summary statistics of soil properties, topographic and vegetation attributes used in developing the unsaturated soil hydraulic conductivity prediction models

\begin{tabular}{lcccccc}
\hline \multirow{2}{*}{ Parameter } & \multicolumn{5}{c}{ Descriptive statistics } \\
\cline { 2 - 7 } & Mean & Minimum & Maximum & Variance & Standard deviation & Skewness \\
\hline ECRatio (-) & 1.22 & 0.051 & 3.348 & 0.333723 & 0.577687 & 0.822749 \\
SARRatio (-) & 1.4 & 0.075 & 2.97 & 0.668552 & 0.81765 & 0.306609 \\
STI (-) & 0.07 & 0.0254 & 0.1535 & 0.000979 & 0.031294 & 0.514429 \\
SR (-) & 3.68 & 1 & 6 & 3.116463 & 1.765351 & -0.10848 \\
OM (\%) & 2.19 & 0.97 & 3.75 & 1.320498 & 1.149129 & 0.417279 \\
MC (\%,db) & 10.4 & 5.35 & 15.16 & 8.666136 & 2.94383 & -0.15317 \\
BD (g/cm $\left.{ }^{3}\right)$ & 1.64 & 1.22 & 1.77 & 0.009861 & 0.099301 & -1.6121 \\
\hline
\end{tabular}

Table 3. Calculated coefficient correlations between used variables

\begin{tabular}{|c|c|c|c|c|c|c|c|}
\hline Variable & ECRatio & SARRatio & STI & SR & $\mathrm{OM}$ & MC & BD \\
\hline ECRatio & 1 & & & & & & \\
\hline SARRatio & 0.588 & 1 & & & & & \\
\hline STI & -0.419 & -0.725 & 1 & & & & \\
\hline SR & 0.001 & -0.133 & 0.253 & 1 & & & \\
\hline $\mathrm{OM}$ & -0.421 & -0.147 & 0.446 & -0.056 & 1 & & \\
\hline MC & -0.428 & -0.462 & 0.675 & 0.013 & 0.802 & 1 & \\
\hline $\mathrm{BD}$ & 0.248 & 0.596 & -0.705 & -0.244 & 0.069 & -0.293 & 1 \\
\hline $\operatorname{LogK}_{U}$ & 0.214 & 0.541 & -0.541 & -0.581 & -0.103 & -0.314 & 0.543 \\
\hline
\end{tabular}

normally distributed. Additionally, Figure (6) shows the scatter plot matrices displaying interrelations between the input variables (i.e ECRatio, SARRatio, soil texture index, suction rate, organic matter in the soil, initial soil moisture content and initial soil bulk density) and unsaturated soil hydraulic conductivity (log $\left.K_{u}\right)$. This figure depicted the dependencies between the unsaturated soil hydraulic conductivity and input variables; however, the existing patterns and trends seem to be relatively complex and difficult. However, it seems that the input variables may directly or indirectly affect the unsaturated soil hydraulic conductivity and thus ANFIS or similar techniques might be useful to be used to derive the functions translating such data into predictions of unsaturated soil hydraulic conductivity.

Table (3) presents the calculated simple linear correlation coefficients (r) between unsaturated soil hydraulic conductivity $\left(\log \mathrm{K}_{\mathrm{U}}\right)$ 
and input variables. It was found that there is a positive correlation between $\log \mathrm{K}_{\mathrm{U}}$ with ECRatio $(\mathrm{r}=0.214)$. Also, positive correlation between $\log \mathrm{K}_{\mathrm{U}}$ with SARRatio was observed $(\mathrm{r}=0.541)$ and positive correlation was observed between $\log \mathrm{K}_{\mathrm{U}}$ with $\mathrm{BD}$ (0.543). It is demonstrated that negative correlations were observed among $\log \mathrm{K}_{\mathrm{U}}$ with STI ( $\mathrm{r}=-0.541)$, with SR $(\mathrm{r}=-0.581)$, with OM $(\mathrm{r}=-0.103)$ and with MC $(r=-0.314)$. This indicates that increasing values of OM, MC and STI of soil will decrease unsaturated soil hydraulic conductivity. Performance of ANFIS model for unsaturated soil hydraulic conductivity prediction

A plot of the predicted unsaturated soil hydraulic conductivity by the ANFIS model versus testing data (Figure 7) and Figure (8) shows the scatter plot and line of best fit. The two figures show that the model captured the relationship between the input parameters and unsaturated soil hydraulic conductivity. The coefficient of

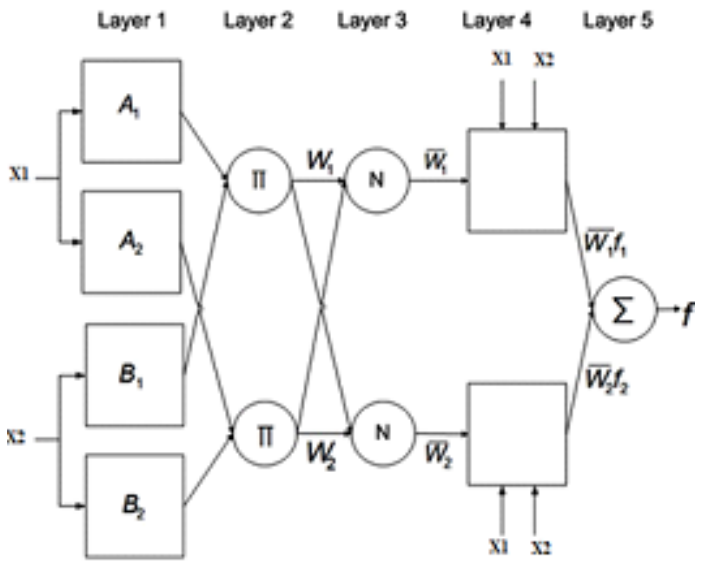

Fig. 1. ANFIS architecture determination $\left(\mathrm{R}^{2}\right)$ was 0.7834 . This value shows that ANFIS can estimate unsaturated soil hydraulic conductivity with a high accuracy. ME and RMSE values for the ANFIS model for testing data are $0.118 \mathrm{~cm} / \mathrm{sec} 0.472 \mathrm{~cm} / \mathrm{sec}$, respectively. By browsing ME and RMSE values and additionally $\mathrm{R}^{2}$ value, it is indicated that the ANFIS model is a useful tool for modeling unsaturated soil hydraulic conductivity. Figure (9) depicts the input-output surface yielded. Focusing on the three dimensional surface graphs of the two selected input and one output, it is possible to conclude that, there are nonlinear relationship among the parameters and unsaturated soil hydraulic conductivity.

a) The present research used the ANFIS and the training data collected through field experiments to construct the predicted model to estimate the unsaturated soil hydraulic conductivity. The predicted model was verified by comparing the

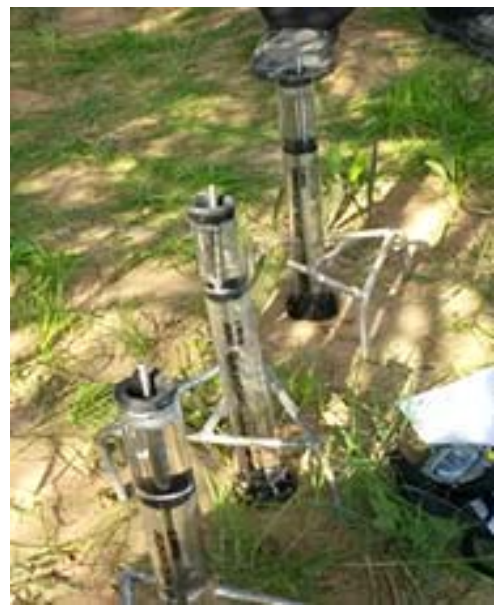

Fig. 2. Mini disk infiltrometer used in the field for measuring unsaturated hydraulic conductivity

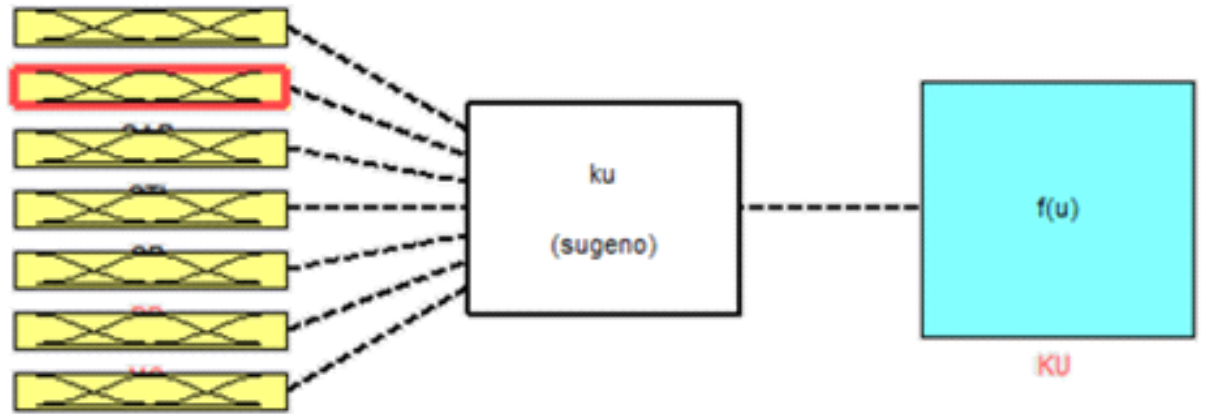

Fig. 3. ANFIS model with seven inputs and one output 

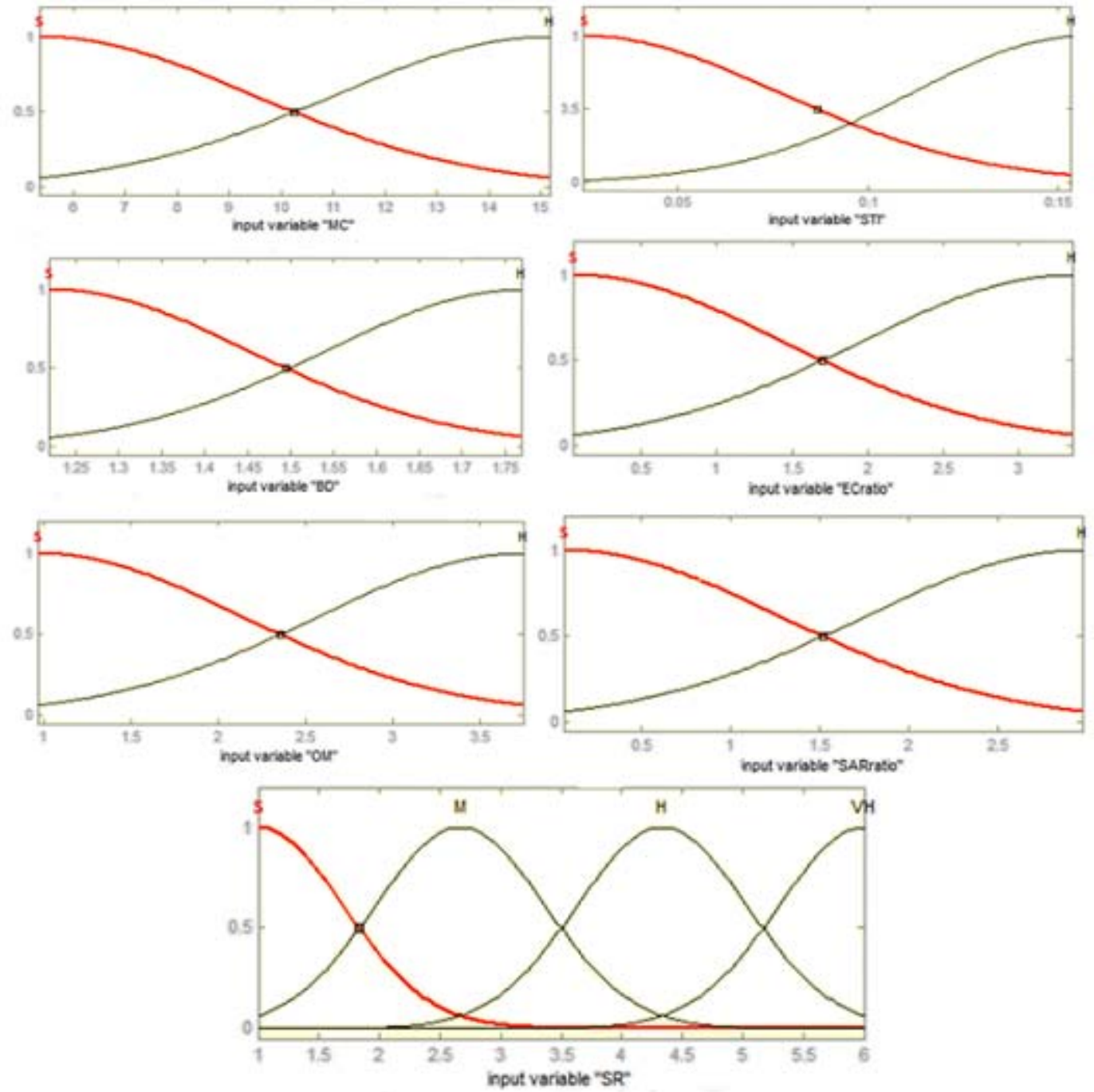

Fig. 4. Final Gaussian membership functions for seven input derived by training process

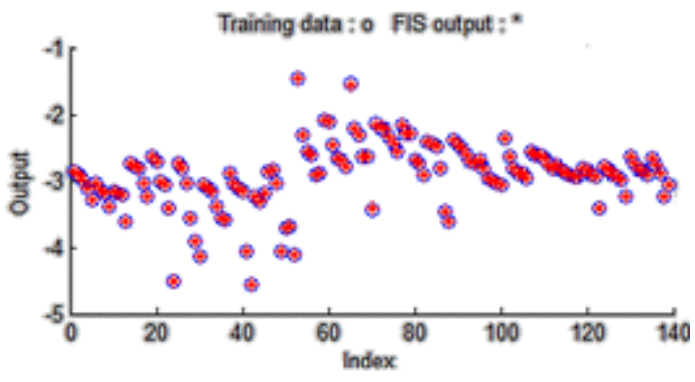

Fig. 5. Pattern of variation of measured and predicted unsaturated soil hydraulic conductivity for the training set predicted values with the checking data. Based on our research, the following conclusions are drawn:

b) The model constructed using the ANFIS (Sugeno method) can effectively predict unsaturated soil hydraulic conductivity by using seven parameters (ECRatio, SARRatio, soil texture index, suction rate, organic matter in the soil, initial soil moisture content and initial soil bulk density).

c) The mean absolute error value equal to 0.472 $\mathrm{cm} / \mathrm{sec}$ suggests that the model is properly trained and appropriate inputs are used for modeling. 


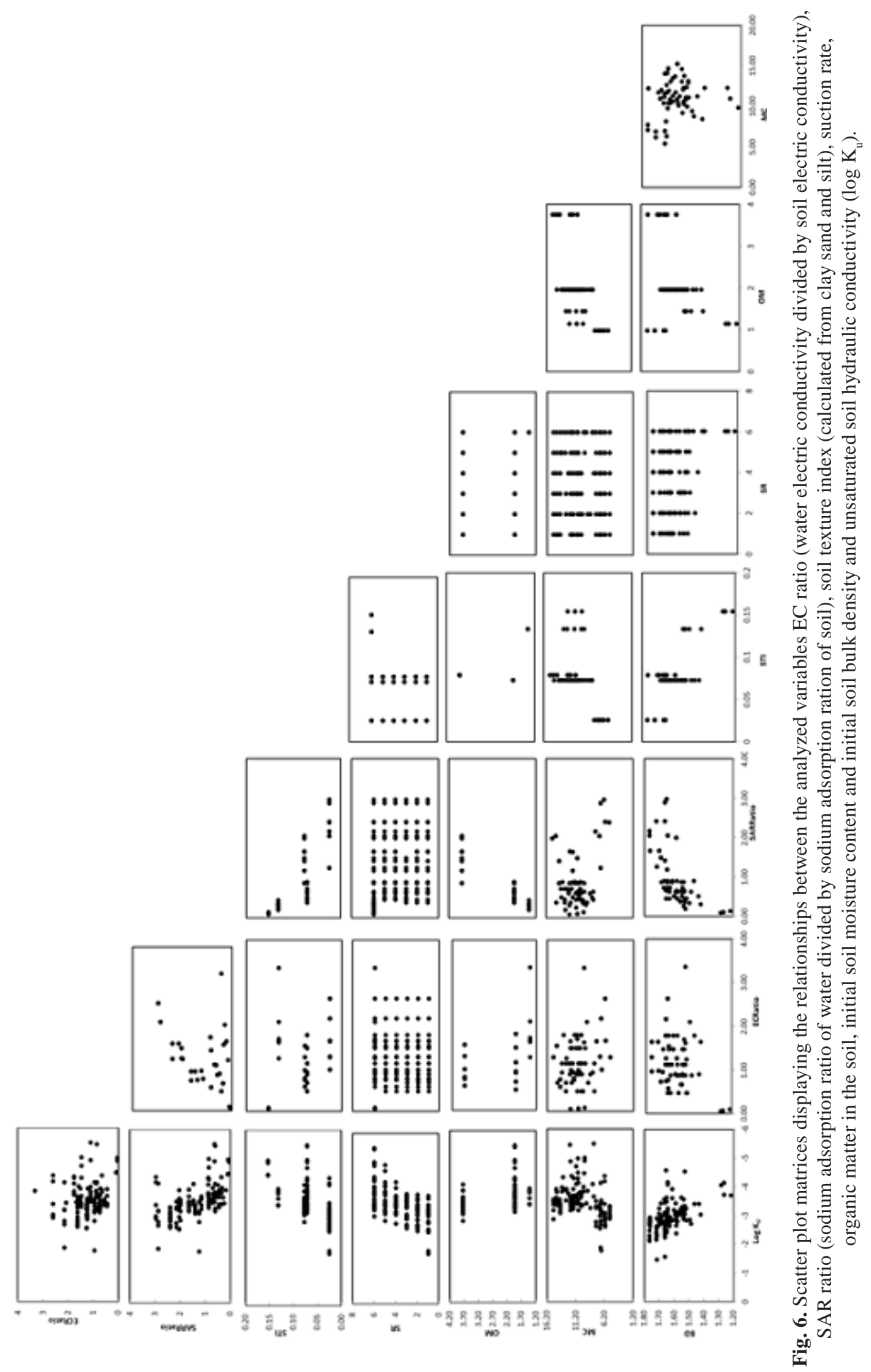




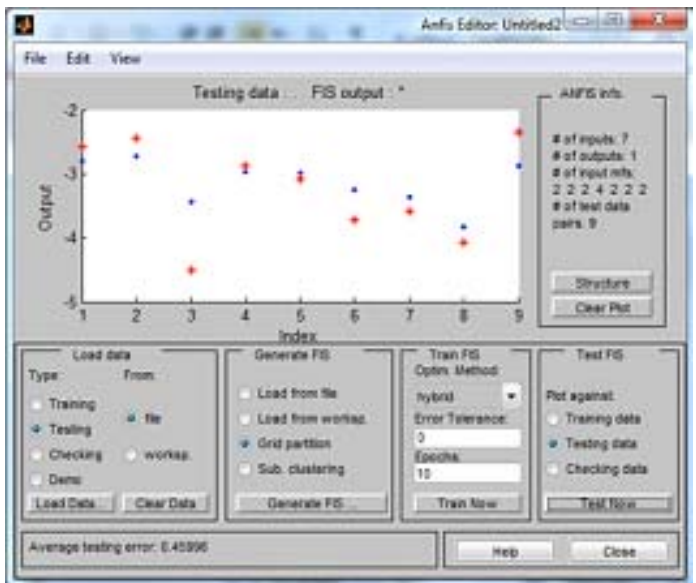

Fig. 7. Testing data and FIS output
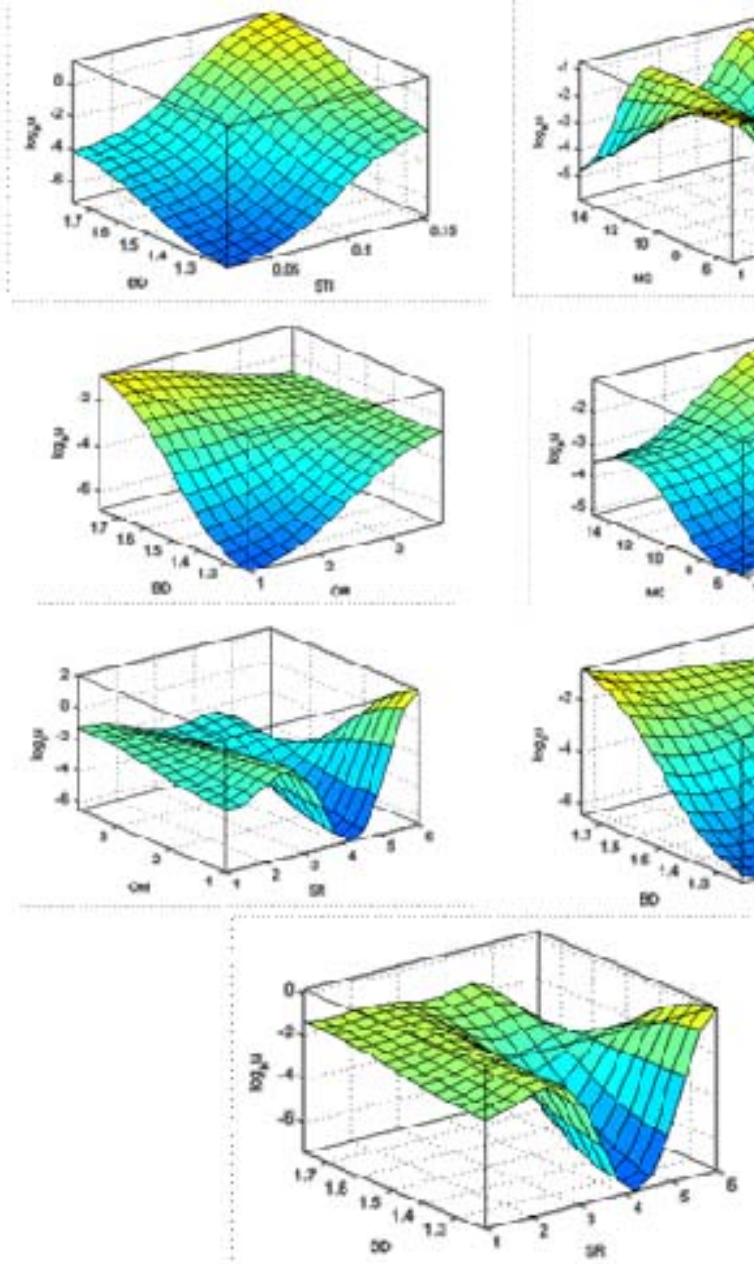

Fig. 9. Diagram of relationship between different input variable and output (log $\mathrm{K}_{\mathrm{U}}$ )
Fig. 8. Scatter plot and line of best fit
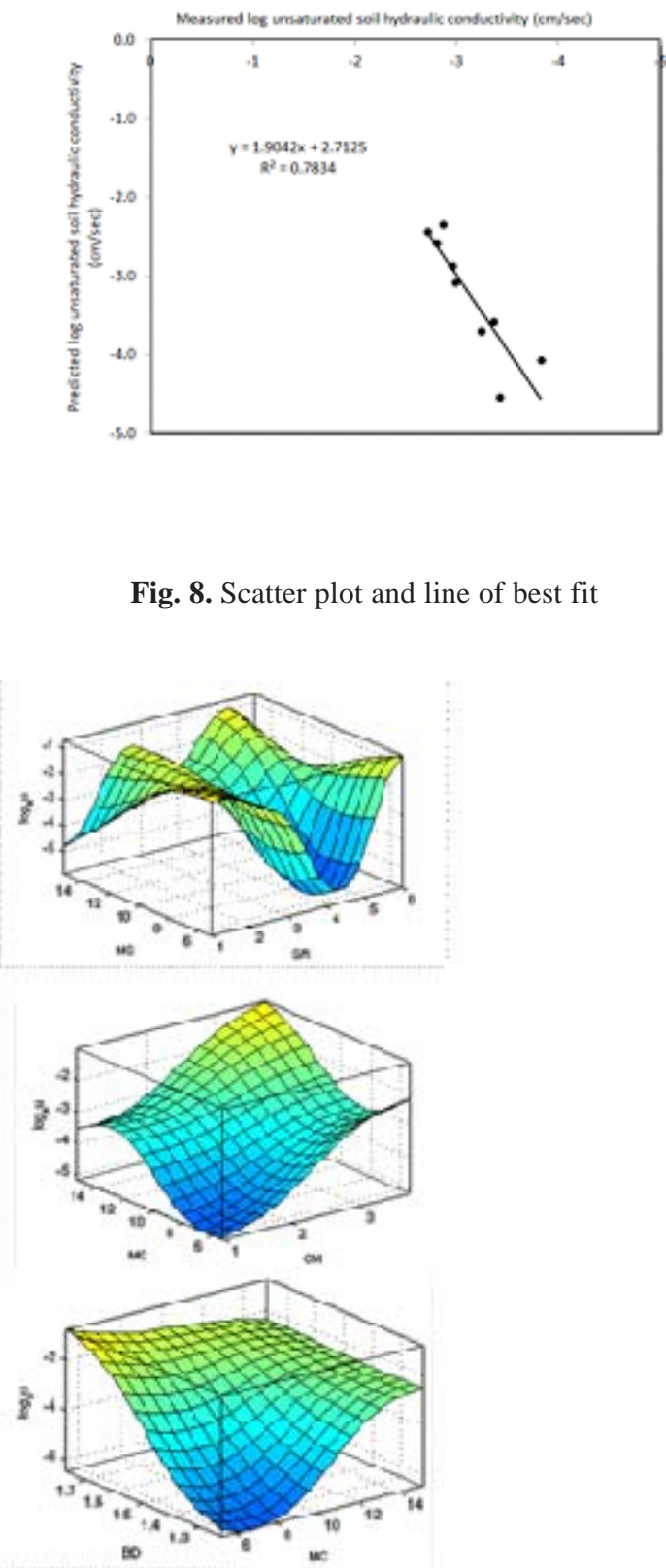
d) The ANFIS could account for approximately $78.3 \%$ of variation in the test data set. In conclusion, the obtained results demonstrate that the ANFIS presented in this study can be used as a tool to predict unsaturated soil hydraulic conductivity.

\section{ACKNOWLEDGEMENTS}

The authors are grateful to King Abdulaziz City for Science and Technology (KACST) for funding of the research project (Grant No. ARP-33-51).

\section{REFERENCES}

1. Akbarzadeh, A., R. T. Mehrjardi , H. R. Lake and H. Ramezanpour, Application of Artificial Intelligence in Modeling of Soil Properties (Case Study: Roodbar Region, North of Iran). Environ. Researc. J., 2009; 3(2): 19-24.

2. Amer, A.M., S. D. Logsdn and D. Davis). Prediction of hydraulic conductivity in unsaturated soils. Soil Sci.,2009; 174 (9):508515.

3. Amer, A.M., W. DeTar and A. F. El-Sharkawy., Hydraulic conductivity and diffusivity as calculated for water field pores in cultivated clay soils. Misr J. Ag. Eng.,2014; 31(3):799-816.

4. Anari, P. L., H. S. Darani and A.R. Nafarzadegan, Application of ANN and ANFIS Models for Estimating Total Infiltration Rate in an Arid Rangeland Ecosystem. Research J. of Environ. Sci., 2011; 5: 236-247.

5. Azamathulla, H. M., C.K. Chang, A.A. Ghani,, J. Ariffin, N.A. Zakaria and Z. Abu Hasan. An ANFIS-based approach for predicting the bed load for moderately sized rivers. J. Hydroenviron. Res., 2009; 3: 35-44.

6. Dane, J.H. and G.C. Topp. Methods of soil analysis, Part 4 physical methods. SSSA, Madison, WI. 2002; 1692.

7. Decagon Devices. Minidisk infiltrometer. User's manual. 2012; 26 p. www.decagon.com.

8. El Awady, M.N., M.H. A. Kabeel, A.M. Aboukarima and Kh. A. Ahmed: Fuzzy logic for prediction soil penetration resistance based on physical properties. The $10^{\text {th }}$ Conf. of Misr Soc. Ag. Eng., 2002; Cairo: 360-372.

9. Elbisy, M. S. Support Vector Machine and regression analysis to predict the field hydraulic conductivity of sandy soil. KSCE Journal of Civil Engineering, 2015.

10. Emami, H. , M. SHorafa, M. R. Neyshabouri .
Evaluation of hydraulic conductivity at inflection point of soil moisture characteristic curve as a matching point for some soil unsaturated hydraulic conductivity models. JWSS - Isfahan University of Technology, 2012; 16(59): 169-182.

11. Erzin, Y., S. D. Gumaste, A. K. Gupta and D. N Singh). Artificial neural network (ANN) models for determining hydraulic conductivity of compacted fine-grained soils. Canadian Geotechnical Journal, 2009; 46(8): 955-968.

12. Fereshte, H. F., Evaluation of artificial neural network and regression PTFS in estimating some soil hydraulic parameters. Pro-Environment, 2014; 7:10-20.

13. Ghanbarian-Alavijeh, B., A.M. Liaghat and S. Sohrabi, Estimating saturated hydraulic conductivity from soil physical properties using neural networks model. International Scholarly and Scientific Research \& Innovation, 2010; 4(2): 108-113.

14. Guber, A.K., Unsaturated soil hydraulic conductivity: The field infiltrometer method. Theory of Methods of Soil Physics, Sein E.V. and Karpachevsky (eds.), Grif and Company Publishing House, Moscow, Russia. 2007; 270273.

15. Ho, W.H., J.X. Chen, I.N. Lee, H.C. Su., An ANFIS-based model for predicting adequacy of vancomycin regimen using improved genetic algorithm. Expert Systems With Applications 2011; 38: 13050-13056.

16. Jabro J. D., Estimation of Saturated Hydraulic Conductivity of Soils From Particle Size Distribution and Bulk Density Data. Transactions of the ASABE. 1992; 35(2): $557-$ 560

17. Jang J.S.R., ANFIS: adaptive-network based fuzzy inference system. IEEE Transactions on Systems, Man, and Cybernetics, 1993; 23(3): 665-685.

18. Kalkhajeh, Y. K., R. R. Arshad, H. Amerikhah and M. Sami. Multiple linear regression, artificial neural network (MLP, RBF) and ANFIS models for modeling the saturated hydraulic conductivity of tropical region soils (a case study: Khuzestan province: southwest Iran. International Journal of Agriculture: Research and Review, 2012; 2(3):255-265.

19. Lakzian, A., M. M. B. Aval and N. Gorbanzadeh Comparison of Pattern Recognition, Artificial Neural Network and Pedotransfer Functions for Estimation of Soil Water Parameters. Notulae Scientia Biologicae, 2010; 2(3):114-120.

20. MATLAB Documentation. Fuzzy Toolbox User's Guide of MATLAB. The MathWorks, 
Inc, 2002.

21. Minasny, B., J.W. Hopmans, T.Harter, S.O.Eching, A.Tuli and M.A. Denton, Neural networks prediction of soil hydraulic functions for alluvial soils using multistep outflow data. Soil Sci. Soc. Am. J., 2004; 68:417-429.

22. Mohdeb, N. and M. R. Mekideche. Determination of the relative magnetic permeability by using an adaptive neuro- fuzzy inference system and 2d-FEM. Progress In Electromagnetics Research B, 2010; 22: 237255.

23. Moosavi, A. A. and A. Sepaskhah. Artificial neural networks for predicting unsaturated soil hydraulic characteristics at different applied tensions. Archives of Agronomy and Soil Science, 2012; 58(2):125-153.

24. Nosrati, K.F., N. S.A.R. Movahedi, A.Hezarjaribi, A.Roshani and A.A. Dehghani, Using artificial neural networks to estimate saturated hydraulic conductivity from easily available soil properties. Electronic Journal of Soil Management and Sustainable Production, 2012; 2(1):95-110.

25. Oskoui, K.E. and S.J. Harvey. Predicting cone index from soil physical properties and organic matter content. ASAE Paper No. 92-1056, ASAE, St. Joseph, Michigan, USA:1-16, 1992.

26. Sarmadian, F. and R. T. Mehrjardi, Development of Pedotransfer Functions to Predict Soil Hydraulic Properties in Golestan Province, Iran. 19th World Congress of Soil Science, Soil Solutions for a Changing World 1-6 August 2010, Brisbane, Australia 2010; 59-62.

27. Schuh, W.M. and J.W. Bauder. Effect of soil properties on hydraulic conductivity moisture relationships. Soil Science Society of America Journal, 1986; 50: 848-855.

28. Sezer, A., A.B. Göktepe and S. Altun. Estimation of the permeability of granular soils using neurofuzzy system. AIAI-2009 Workshops Proceedings 2009; 333

29. Siltecho, S., C. Hammecker, V.Sriboonlue, C.Clermont-Dauphin, V.Trelo-ges, A. C. D. Antonino and R. Angulo-Jaramillo. Use of field and laboratory methods for estimating unsaturated hydraulic properties under different land-use. Hydrology and Earth System Sciences Discussions, 2014; 11(6): 6099-6137.

30. Skaggs, T.H., L.M. Arya, P.J. Shouse and B.P. Mohanty., Estimating particle-size distribution from limited soil texture data. Soil Science Society of America Journal, 2001; 65:1038-1044.

31. Suarez, D. L., J. D. Wood and S. M. Lesch. Infiltration into cropped soils: effect of rain and sodium adsorption ratio-impacted irrigation water. Journal of Environmental Quality, 2008; 37(5)Supplement:169-179.

32. Takagi, T. and M. Sugeno, Fuzzy identification of systems and its applications to modeling and control. IEEE Trans. on Systems, Man, and Cybernetics, 1985; 15: 116-132.

33. Tamari, S., H.M. Wosten and J.C. Ruiz-Suarez. Testing an artificial neural network for predicting soil hydraulic conductivity. Soil Science Society of America Journal, 1996; 60: 1732

34. Torabi, F. N., B.Ghahraman, H.A. Kashkouli and H. S. Mahmoud. Measurement of unsaturated soil hydraulic conductivity and comparison with four estimation models. Iranian Journal of Soil and Waters Sciences, 2006; 20(2): 296-308.

35. Vereecken, H. Estimating the unsaturated hydraulic conductivity from theoretical models using simple soil properties. Geoderma, 1995; 65: 8192.

36. Vereecken, H., J. Maes and J. Feyen. Estimating unsaturated hydraulic conductivity from easily measured soil properties. Soil Science, 1990; 149: $1-12$.

37. Xue, X. and X. Yang.Application of the adaptive neuro-fuzzy inference system for prediction of soil liquefaction. Natural Hazards,2013; 67: 901-917.

38. Yan, H., Z. Zou and H. Wang. Adaptive neuro fuzzy inference system for classification of water quality status. Journal of Environmental Sciences, 2010; 22(12): 1891-1896.

39. Yilmaz, I. and O.Kaynar. Multiple regression, ANN (RBF, MLP) and ANFIS models for prediction of swell potential of clayey soils. Expert Systems with Applications, 2011; 38: 5958-5966.

40. Zadeh, L., Fuzzy set. Information and control, 1965; 8: 338-353.

41. Zhang, R., Determination of soil sorptivity and hydraulic conductivity from the disk infiltrometer. Soil Science Society of America Journal, 1997; 61:1024-1030.

42. Zhuang, J., K. Nakayama, G.R. Yu and T. Miyazaki., Predicting unsaturated hydraulic conductivity of soil based on some basic soil properties. Soil \& Tillage Research, 2001; 59: 143-154. 